\title{
Quadrinhos - A LINGUAGEM COMPLETA
}

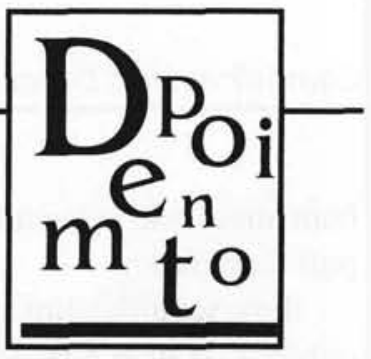

\author{
As histórias em quadrinhos são, para muitas \\ crianças, o primeiro contato com o universo \\ das letras e das imagens. Contando sua \\ experiência com essa linguagem, o \\ desenhista e cartunista JAL defende o uso \\ das HQs em sala de aula como forma \\ de estimular a leitura e a criatividade \\ dos alunos.
}

No momento em que o visual, o grafismo, toma conta de nossos meios de comunicação, as histórias em quadrinhos se colocam como uma forma de unir o visual e a palavra numa mescla mágica de várias linguagens artísticas. Nesta mágica, que surgiu junto com o cinema, encontramos tanto a arte gráfica quanto a literatura e a agilidade do cinema. Melhor ainda, os quadrinhos dão chance de seu leitor usar a imaginação criadora. Enquanto o cinema e a TV nos dão imagens prontas, sem possibilidade de retorno, a não ser através de um videocassete acoplado, o quadrinho mostra uma seqüência intercalada por espaços vazios, onde nossa imaginação cria imagens de ligação. Entre um quadrinho e outro, a ação tem continuidade na cabeça do leitor.

\section{O AUTOR}

JAL - José Alberto Lovetro

Jornalista e cartunista, já trabalhou em Folha de S. Paulo, O Estado de S. Paulo, Diário do Comércio e da Indústria/Shopping News, revistas Visão, Veja, TVs Cultura, Manchete, Tupi, Record, Bandeirantes, Gazeta e Globo. Atualmente trabalha em sua empresa Auika Desenhos Artísticos, tem os direitos e publica novas piadas do personagem Amigo da Onça, publica seus personagens infantis Sport Gang no jornal Kid News, além de ministrar cursos de quadrinhos para a Secretaria da Cultura do Estado.

Outro fator importante que acontece com os quadrinhos, é a possibilidade de podermos imaginar as vozes dos personagens. É diferente de um livro, por exemplo, que não nos oferece este tipo de apelo visual. Quando lemos e vemos o personagem daquela fala, nossa tendência é interpretá-lo com maior dramaticidade e convicção. Como pode ver a cena, o leitor de quadrinhos é praticamente co-autor da história. Se antigamente chegava-se a culpar as HQs pela criminalidade 
infantil ou por tomar o tempo de estudo das crianças, hoje a situação é outra. Atualmente o ensino necessita desta linguagem para auxiliar o aprendizado da criança.

\section{É verdade que até agora as histórias em quadrinhos não foram utilizadas de forma correta no ensino formal.}

Em primeiro lugar, por falta de profissionais especializados e também por desinformação das editoras, que, para fazer economia, não contratam pessoas capacitadas, além de não desenvolverem nenhum estudo mais sério sobre como passar informações úteis às crianças através dos quadrinhos.

Em cursos e workshops que desenvolvi com alunos das mais diversas idades em várias cidades do país, descobri que o que move alguém a se interessar pelos quadrinhos, independente de idade ou sexo, é o encanto do desenho. Tanto crianças como adultos gostam de ter o poder de criar uma imagem sobre um papel. Depois, vem a identificação com o personagem e a vontade de ler suas aventuras. O impacto visual é sempre a "mola" que move a vontade de ler.

A falada co-autoria do leitor não se restringe à criação dos timbres de vozes, das entonações ou da continuidade das seqüências, ela o leva também à interpretação dos diversos sons emitidos - graças a uma grande criação das HQs: a grafia da onomatopéia.

Os sons transformados em palavras são mágicos e dão a acústica da ação. Enfim, é uma linguagem que não serve apenas ao contador de histórias, mas também ao médico que precisa explicar às pessoas menos informadas sobre como evitar o Cólera, ou ao advogado que defende seu cliente com explicações mais detalhadas da ação, como aconteceu recentemente no Rio Grande do Sul. Há pouco tempo atrás, executei um trabalho para o Liceu de Artes e Ofícios de São Paulo, que completava 120 anos de vida e precisava falar ao público jovem, explicando seu atual funcionamento, seus cursos e ainda contar sua história. Eu e uma equipe fizemos uma revista de 32 páginas com uma história de fundo que expunha todos estes itens. Foram impressas 400 mil revistas e encartadas numa edição do jornal $\mathbf{O}$ Estado de $\mathbf{S}$. Paulo. Para a empresa/escola foi o suficiente para atingir seu públicoalvo, gastando menos que um comercial de TV e com maior eficiência. Foi aí que percebemos que esta linguagem já não é mais a daquele "gibizinho" que apenas divertia as crianças nas horas de folga.

Sua importância cresce ao se constatar que realmente o gibi é o primeiro livro de leitura de uma criança. Não dá mais para deixar de usá-lo. 


\section{A PRODUÇÃO DE UMA REVISTA DE HISTÓRIAS EM QUADRINHOS}

Para entender a arte e produção dos quadrinhos é preciso ter em mente suas possibilidades em nosso universo de Terceiro Mundo, onde o fator econômico se torna uma imposição à qualquer ativida-

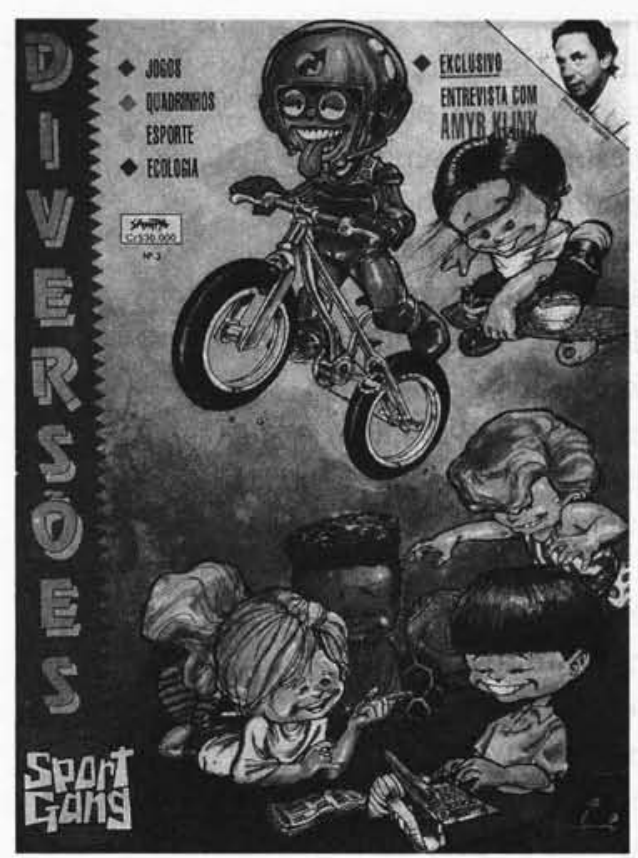

Revista "Sport Gang" criada em 1990 no formato de jornal. Em 1992, transformou-se em revista. de. Observemos a dificuldade de publicar um livro, sobretudo se sua tiragem não puder ser grande. Mais difícil ainda é produzir um filme ou até um programa de TV, onde o investimento é altíssimo e nem chega perto, na maioria dos casos, se o compararmos ao investimento de outros países mais desenvolvidos na área.

No entanto, na área dos quadrinhos, o desnível praticamente não existe. Os artistas nacionais nada ficam a dever aos estrangeiros. Competem de igual para igual no campo artístico. Existem várias editoras neste setor e as tiragens são bem maiores que as de muitos livros. Seu potencial de público é tão grande quanto o do cinema. O que mais pode encarecer o quadrinho talvez seja sua publicação em cores, mas este não é ponto básico para seu sucesso.

O Brasil desenvolveu seu mercado de quadrinhos mais voltado ao segmento infanto-juvenil. Histórias de humor e de super-heróis dominaram as bancas até pouco tempo. O desenvolvimento de um mercado de publicações adultas, com textos mais densos e de valor plástico em nível de outras artes como a pintura, deu-se há pouco mais de uma década. $\mathrm{O}$ resultado imediato disso é a melhora do nível de leitores e produtores de HQs no País.

Podemos, então, dividir sua produção em basicamente duas categorias: a do quadrinho de autor e a do quadrinho de produção em escala industrial.

Estas categorias são ditadas tanto pelo autor da obra como pelo próprio mercado. Quadrinho de autor seria aquele que depende diretamente do criador ou criadores para sua execução. Como por exemplo, o caso do cartunista Angeli, que cria e desenha suas histórias pessoalmente. Às vezes pode haver um desenhista ou roteirista trabalhando em conjunto, como quando Angeli se junta ao Glauco e ao Laerte para produzir Los Tres Amigos. 
Já no caso do quadrinho em escala industrial, existe a necessidade de o autor criar um grupo para desenvolver uma quantidade maior de páginas para atender à produção. Maurício de Sousa, por exemplo, criou seus personagens, mas a partir de certo momento, quando precisou produzir mais páginas por mês (hoje em dia produz até 300 páginas de HQs mensais), teve que montar uma equipe, onde alguns criam roteiros, outros fazem o esboço a lápis, outros passam a tinta sobre o desenho, outros fazem as letras dos balões e, ainda, outros indicam as cores a serem aplicadas na gráfica. Devido à maior produção, este tipo de quadrinho tem maior possibilidade de merchandising (utilização dos personagens na venda de produtos e brinquedos) do que o quadrinho de autor.

\section{O PROCESSO DE CRIAÇÃO DAS HQs}

Antes de tudo, para se aventurar na área dos quadrinhos, é preciso que o autor tenha conhecimento do mercado onde pretende publicar e comercializar sua arte.

Uma HQ não é um quadro de pintura que por si só sobrevive como obra artística, ela depende do processo gráfico e de sua comercialização em bancas de jornais e livrarias.

Deve-se pensar não apenas em sua execução, mas principalmente a que público ela se dirige. Se não se importar com estes fatores, suas possibilidades de vendagens serão bem menores.

A formação de um argumentista e criador de personagens não pode ficar restrita apenas à leitura de quadrinhos.

Um roteirista de HQ tem que ter formação de escritor. Ser bem informado sobre a história da humanidade, assim como sobre seus movimentos artísticos e fatos jornalísticos mais atualizados. Afinal, o quadrinhista é um comunicador e deve estar melhor informado do que seu grupo de leitores.

É recomendável, antes da criação de um roteiro, muita leitura e, principalmente, bastante pesquisa sobre $o$ assunto a ser tratado. Alex Raymond, criador do personagem Flash Gordon em 1929, pesquisava física, astronomia e se interessava por inventos para aplicar em suas histórias futuristas. Um de seus inventos para Flash Gordon se locomover no espaço sem atração gravitacional, os 
jatos acoplados às costas de seu traje espacial, foi utilizado muitos anos mais tarde pela NASA. Por aí se observa o valor até científico dos quadrinhos e sua influência na História.

Para criar um personagem também é preciso pensar em todo o universo de coisas que o cercam - de onde ele vem, quem são seus pais, amigos, inimigos e quais as suas preocupações.

Quanto mais forte e fundamentada for a personalidade, maiores os pontos de identificação com seu público-alvo. Quando pensei em criar personagens do mundo infantil, por exemplo, analisei os que já estavam nas bancas de jornal e os que foram criados no passado. Percebi que não havia um grupo de personagens infantis ligados ao esporte, onde cada um apreciasse um tipo de modalidade diferente. Havia o Pelezinho de Maurício de Sousa, mas não um grupo.
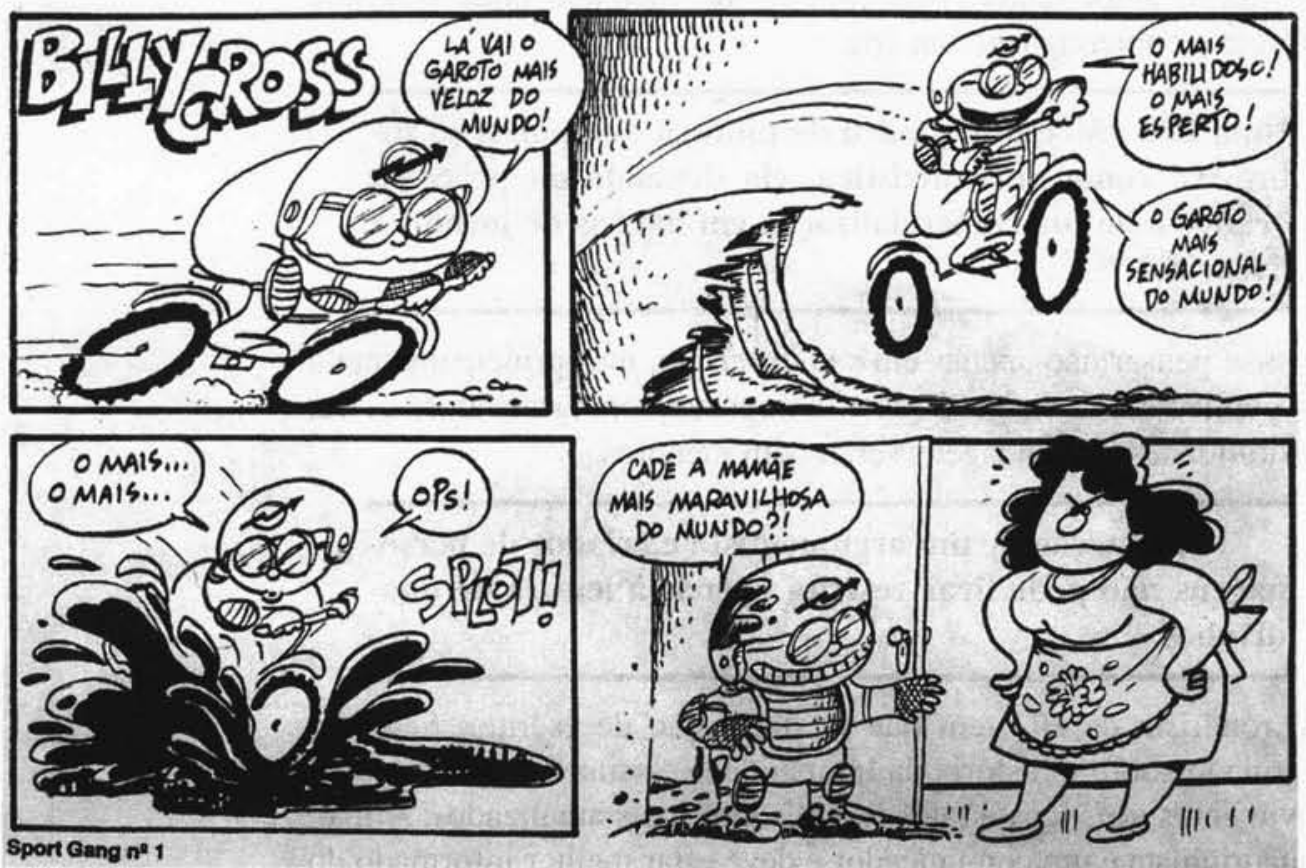

Tira de personagem ligado ao esporte e à ecologia

A importância de colocar no mercado e encontrar brechas onde a concorrência é menor, é ponto básico para se obter sucesso. Vejam que existem vários personagens baseados em gatos, cachorros e coelhos animais domésticos que fazem parte do dia-a-dia das pessoas. Porém, criar mais um personagem gato para um mercado que já tem Garfield, Tom (da dupla com Jerry), Mandachuva, Gato Félix e outros, terá que ter características muito marcantes para se impor no mercado. 
Já na questão gráfica, é necessário que o desenhista faça uma análise da tendência nesta área para estar em sintonia com o público leitor.

Traços simples para personagens de humor e mais "acadêmicos" para histórias de aventura são quase que regra para as editoras, mas nem sempre são a fórmula do sucesso.

A fase seguinte é a elaboração do roteiro - e é aí que reside o maior número de falhas. Para contar uma história é necessário montar uma estrutura com uma proposta a ser abordada e a definição de início, meio e fim. O leitor tem que estar preso do primeiro ao último quadrinho. Se um editor pede ao autor para que faça uma história dentro de um certo número de páginas para sua revista, o artista deve dividi-la nesta estrutura de maneira uniforme. $\mathrm{O}$ começo tem que ser arrebatador e as páginas intermediárias precisam manter o nível de curiosidade e suspense para chegar a um final que dê margem ao questionamento do enredo.

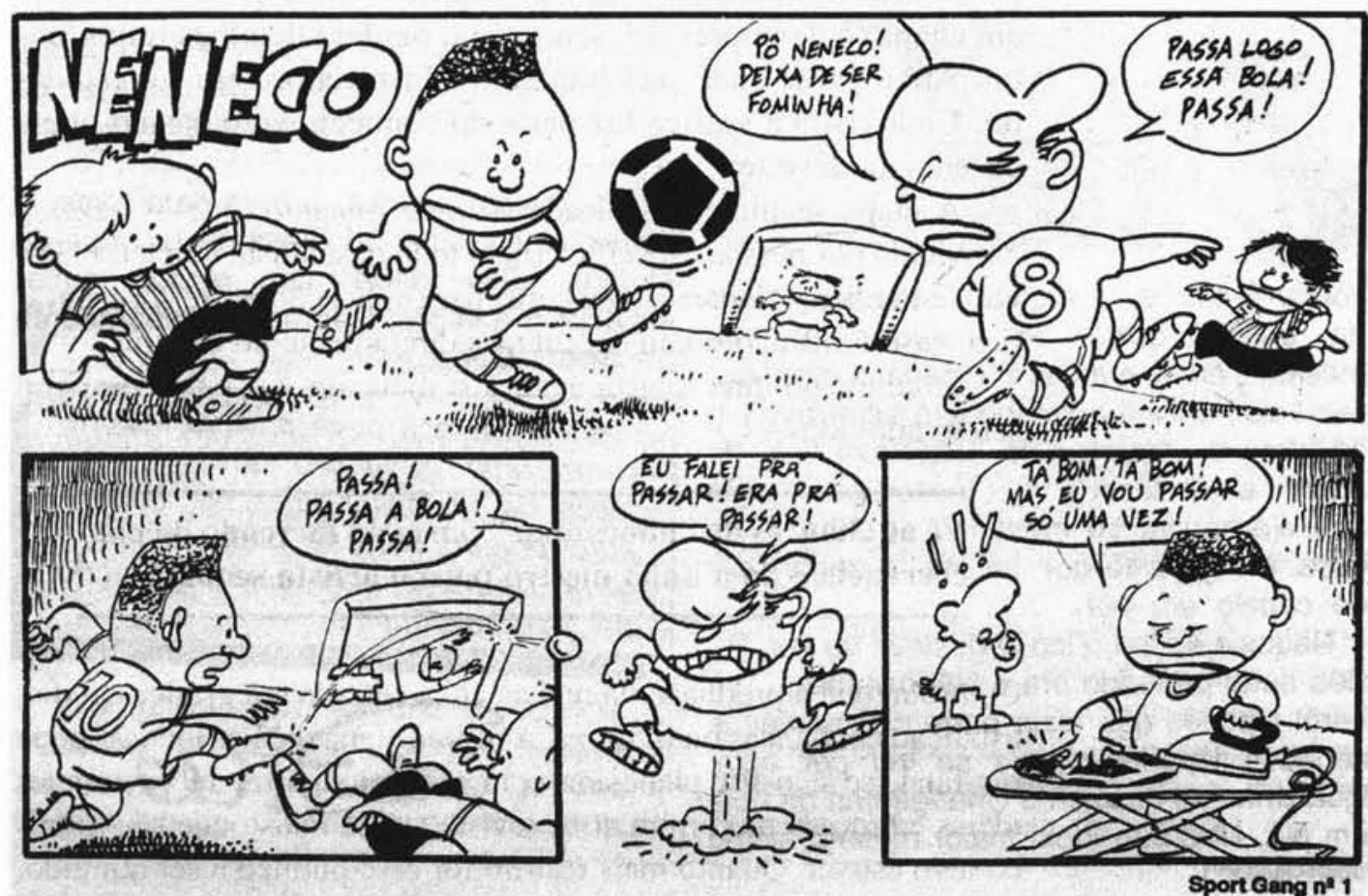


Para se ter uma idéia mais simplista desta estrutura, pode-se tomar como exemplo as tiras diárias publicadas em jornais - uma história contada basicamente em três quadrinhos, cada qual representando uma fase: início, meio e fim.

Depois da elaboração do roteiro, tem-se o esboço ou rascunho executado sobre o primeiro. Este rascunho serve para estudar os ângulos de desenho e quadrinhos que mereçam maior destaque que outros na sequiência narrativa. É uma diagramação prévia, inclusive de balões com textos, cuja finalidade é manter a estética do desenho. A colocação dos balões é importante para o entendimento dos diálogos.

\section{Ao evitar usar muito texto em um só quadrinho ou que os balões encubram o rosto ou a ação de uma imagem, a narrativa só tem a ganhar.}

Chegamos, então, à arte-final, onde o desenhista passa a tinta sobre o esboço dando os contornos finais ao desenho. Nesta fase, pode-se usar uma série de técnicas com pincéis, canetas e até lápis. $\mathrm{O}$ artista tem apenas que conhecer bem o processo gráfico que vem a seguir, para saber que se fizer traço a lápis será necessário um bom processo de fotolito (filme para a gravação em chapa) e de impressão, sem o qual perderá detalhes importantes. Até o papel onde será impressa a história precisa ser estudado. Uma visita à gráfica faz parte do conhecimento básico que o desenhista deve ter.

A etapa seguinte é dedicada ao letreiramento, que às vezes é executado por pessoa específica (nem todo desenhista tem letra legível), e também à indicação de cores para aplicação posterior na gráfica, caso estas não sejam executadas diretamente no original.

$\mathrm{O}$ editor de uma revista analisa o mercado e o público-alvo a serem atingidos.

Vê as chances de "abocanhar" parte do mercado da concorrência e dá a linha mestra para 0 artista seguir.

Controla toda a produção da revista até a entrada em gráfica e a distribuição em bancas ou livrarias. A última etapa da distribuição pode ser fatal, se não for planejada com a distribuidora. Já vi grandes idéias editoriais morrerem aí. A revista vende mais onde seu público-alvo estiver. Quanto mais restrito for esse público a ser atingido, mais planejamento de distribuição será necessário. 
Eu editei uma revista de quadrinhos para um público jovem e de vanguarda que só vendia bem nas capitais mais desenvolvidas do País. Quando percebemos o erro de distribuição e o "encalhe" de revistas, abortamos sua continuidade e não tínhamos mais dinheiro para financiar o número dois.

Todas estas fases da leitura de uma revista de quadrinhos podem ser treinadas em uma sala de aula por alunos que a finalizem em impressão xerox.

Com isso, consegue-se maior experiência na organização de um grupo de comunicação e pode-se encaixar várias alternativas. Se um aluno não sabe desenhar, pode trabalhar com colagens ou fotonovela ou até fazer apenas texto. Não é necessário ser um desenhista para desenvolver uma $\mathrm{HQ}$. Para se criar um personagem, também é preciso criar sua roupa. Algum aluno pode ser o estilista. $\mathrm{O}$ tipo de cabelo, maquiagem... Tudo no quadrinho é um exercício de alguma atividade profissional.

Trabalhar com a linguagem dos quadrinhos em sala de aula é quase que obrigatório nos dias atuais. A técnica dos $C D-R O M$ para vídeo em computadores terá o mesmo tipo de linguagem.

Portanto, ao invés de uma simples composição, o professor pode pedir aos alunos que desenvolvam uma $\mathrm{HQ}$, e nem por isso estará deixando de ensinar literatura.

Estou tão sintonizado com essa idéia que já estou desenvolvendo um livro com exercícios específicos para a sala de aula. Com isso, a criatividade do aluno é aguçada para o texto e desenvolvimento de novas idéias. Acredito firmemente que está aí uma das formas de melhorarmos o ensino no Brasil. 